\title{
Optimal Design of an IPM Motor for Electric Power Steering Application Using Simulated Annealing Method
}

\author{
Hamidreza Akhondi, Jafar Milimonfared and Hasan Rastegar \\ Amirkabir University of Technology \\ Iran
}

\section{Introduction}

Electric power steering (EPS) in newer vehicles is becoming an alternative to the hydraulic power steering (HPS) because of the recent advances in electrical motors, power converters, sensors and digital control systems (Mir et al., 2003). In the EPS system, an electric motor is connected to the steering rack via a gear mechanism. Some sensors measure the torque on the steer and the angular position of the hand wheel. A control system receives these signals from the sensors, together with vehicle speed, turning rate, and gives operating commands to the electric motor drive, controlling steering direction and dynamics and driver effort. The control unit determines the amount of steering assist torque, which has to be also modified according to vehicle speed to maintain good steering feel.

Electric power steering eliminates the need for a hydraulic power steering pump, hoses, hydraulic fluid, drive belt and pulley on the engine, therefore the total system is lighter than a comparable hydraulic system through the use of compact system units (Mir et al., 2003). Also, since EPS is an on-demand system that operates only when the steering wheel is turned, the fuel efficiency of vehicle equipped with such system is better than that of automotive equipped with an equivalent-output hydraulic system (Liao \& Isaac, 2003). As a result, Electric power steering systems have many advantages over traditional hydraulic power steering systems in engine efficiency, space efficiency, and environmental compatibility. This motivates the great increase of EPS-equipped automotive recently (wilson, 2005).

Electric power steering basically consists of a torque sensor and motor actuator couple. The sensor is attached to the steering column and measures the torque applied by the driver for moving the steering wheel. This torque signal is transmitted to a control power card that sends an amplified proportional power signal to the electric motor (in this paper we use interior permanent magnet (IPM) synchronous motor), which is engaged to the steering rack bar.

An EPS system has the following two functions. First, it can reduce steering torque and present various steering feels. The steering torque (or driver torque) is defined as the one which a driver experiences (or a driver applies to the steering column) when turning the steering wheel. When an appropriate assist torque from an EPS system is applied in the 
same direction as the driver's steering direction, the amount of steering torque required by a driver for steering can be significantly relieved. In addition, adjustment of the characteristics of assist torque allows the driver to experience various steering feels. Second, the EPS system can improve return to center performance of a steering wheel when it is steered. While the steering wheel is turned and then released during cornering, it returns to the center position by the so-called self-aligning torque exerted on the tires by the road. Since this torque increases with vehicle speed, at high vehicle speeds the steering wheel may exhibit excessive overshoot and subsequent oscillation. The EPS system can eliminate this phenomenon by providing active damping capability, thus enhance return ability characteristics.

This paper presents an Electric Power Steering system using IPM motor and drive system which is widely being applied in automotive applications. Due to factors such as high power density and efficiency, maintenance, and extremely wide operating speed range, permanent magnet synchronous motors (PMSM) are the subject of development for traction drive applications (Jahns et al., 1986).

Optimization with Simulated Annealing (Ingber, 1993) method is done on the IPM motor structure considering the EPS requirements and constraints to obtain the motor parameters. So the paper deals with the design and performance evaluation of an IPM motor for EPS system. The components of system such IPMSM electrical and mechanical parts, power electronic converter, steering mechanism and controller are integrated as entire model of EPS using Simulink environment for analyzing the system performance with interactions between each component. The block diagram of EPS with IPMSM drive system is shown in Fig. 1.

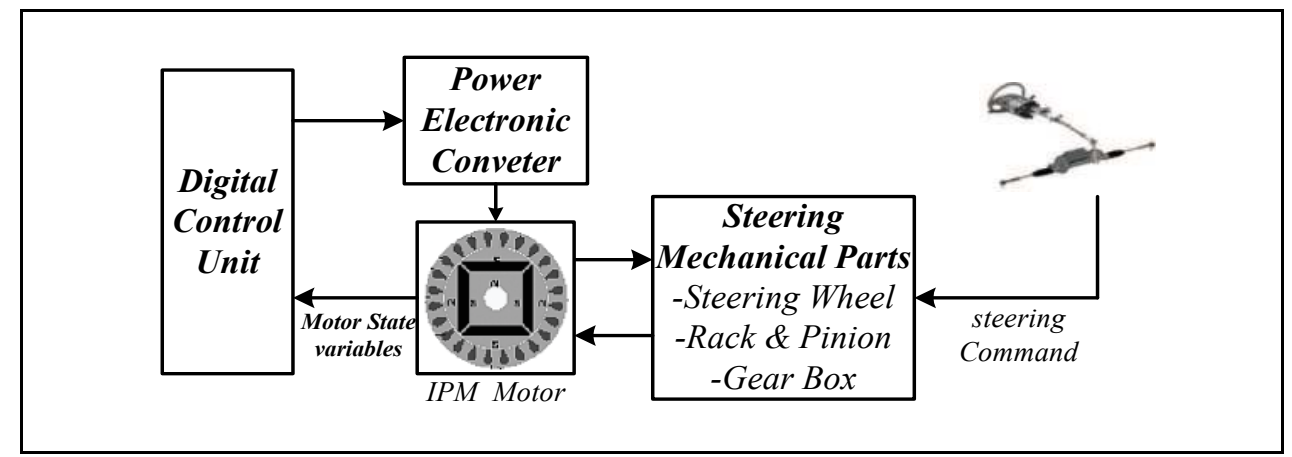

Fig. 1. Block Diagram of Overall EPS System

\section{Optimization of the IPM Motor Parameters}

The IPM motor presents many advantages over the other motors. Among them, it exhibits high torque density, yielding a minimum size and weight, good power to weight ratio as demanded in automotive applications (Chedot \& Friedrich, 2003) and a high efficiency, even under reduced loads. In addition, its manufacture is easy, because the PMs are simply introduced in suitable holes in the rotor and the motor has capability to operate in flux weakening region. So for the IPMSM, the magnetic circuit has been fully designed using the optimization from analytic and finite-element based software. 
In this design, the objectives to be reached are the reduction of the volume and total weight as well as the reduction of the size of the magnets to decrease the cost (Sebastian et al., 2004). An easiness of the manufacturing process must be kept in mind for a future industrial application. Other objectives as the dynamic behavior and the torque ripple will be examined in the future with the power electronic and control interactions.

Taking into account the important number of design variables, an optimization under constraints is chosen. Variables are classified into discrete and continuous one. If discrete variables are fixed (for example number of stator slots) a non-linear mathematic algorithm can be used to optimize the machine structure with geometrical constraints. A number of optimization variables noted $U$ are selected in order to find optimal values noted $U^{*}$ as shown below.

$\mathrm{U}^{*}$ minimizes an objective function $\mathrm{F}$ and verifies the feasibility domain under constraints:

Minimize $\mathrm{F}(\mathrm{U})$

Subject to

$$
\mathrm{U}^{*} \in \mathrm{U}
$$

$$
\begin{aligned}
& \mathrm{H}_{\mathrm{i}}\left(\mathrm{U}^{*}\right)=0 \\
& \mathrm{G}_{\mathrm{i}}\left(\mathrm{U}^{*}\right) \geq 0 \\
& \mathrm{U}_{\ell_{\mathrm{i}}} \leq \mathrm{U}_{\mathrm{i}} \leq \mathrm{U}_{\text {ui }}
\end{aligned}
$$

$\mathrm{U}^{*}$ must permit to reach the desired goal with the minimization criterion. It must also verify the equality and inequality constraints while keeping in the range of allowed values. For example, if the power to weight ratio has to be limited, it is necessary to choose:

$\mathrm{U} \rightarrow$ motor parameter (magnet flux linkage \& dimensions)

$\mathrm{F}(\mathrm{U}) \rightarrow$ power to weight ratio

$\mathrm{G}_{1}(\mathrm{U}) \rightarrow$ external diameter $\leq \mathrm{D}_{\max }$

...

$\mathrm{G}_{\mathrm{i}}(\mathrm{U}) \rightarrow$ motor torque $\geq \mathrm{T}_{\min }$

The method is based on an analysis and optimization parts. The analysis part uses the parametric model with the variables $U$ to calculate the energetic values of the machine according to design specifications. The analysis part treats three domains (Fig.2). The magnetic domain is the first and the central one because it is coupled with the two others. It allows the evaluation of inductance and back-emf. This brings to electromechanical performances. The thermal domain gives temperature of magnets and copper to estimate flux density and resistances. The electrical domain gives the relationship between the current reference and the real current according to the voltage limit.

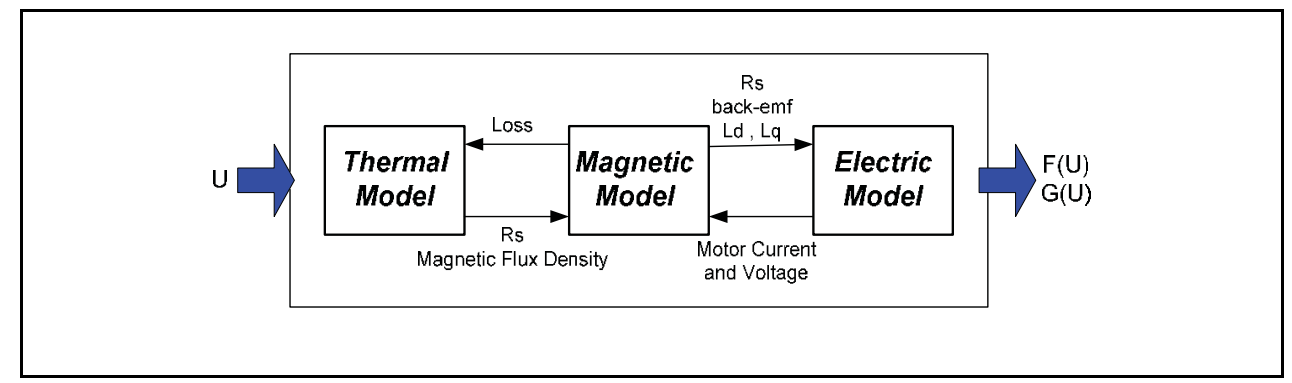

Fig. 2. Analysis module in optimization process 
The optimization part manages the variables $U$ on the basis of $F(U)$ and $G(U)$ information given by the analysis part. In this paper the Simulated Annealing Method (SA) is used in optimization part. The SA algorithm mainly consists of repeating a sequence of iterations. Given an optimization problem, at a selected initial temperature, the SA starts off with the initial solutions: current and trial, randomly selected from two points within the search space. Two energy level sets of current solution and trial solution, Ei and Ej respectively, are obtained. The Metropolis algorithm, generation and acceptance is then applied. If $\mathrm{Ej}-\mathrm{Ei}<0$, then the trial solution is accepted and replaces the current solution. Otherwise, the acceptance or rejection is based on Boltzmann's probability acceptance, which is $P A=\exp \left(-\frac{E i-E j}{K T}\right)$ where $\mathrm{T}$ denotes the temperature, $\mathrm{k}$ is Boltzmann's constant. If $\mathrm{PA}$ is higher than $\mathrm{R}$, where $\mathrm{R}$ is a random value $(0-1)$, the trial solution is accepted and replaces the current solution. If PA is less than $\mathrm{R}$ then the current solution remains and a new trial solution is generated. The generation mechanism and acceptance criterion are then repeated. After a certain amount of iterations, the temperature is reduced by multiplying its value by a factor slightly below one. With reduced temperature, these two processes are repeated again until the criterion of execution is achieved (Ingber, 1993).

The final machine parameters after optimization with this method is given in table 1.

\section{Modelling of EPS with IPM Motor and Drive}

Typical EPS system is shown in Fig. 3. The major components are a torque sensor, an electric motor, a reduction gear and control unit. Torque sensor is located between steering wheel and steering column and measures the applied torque by converting difference of twisted angle to electric signal. The electric motor is attached in steering column through reduction gear box. Control unit calculates motor target torque and current from the signal of torque sensor and vehicle velocity. So the calculated torque is applied to steering column by motor through reduction gear.

There are four different type of EPS, column, pinion and rack-assisted or a fully steer by wire type (Mohammadi \& Kazemi, 2003). In this paper, a column-assist-type EPS shown in Fig. 3 is used for modeling and simulation. The equilibrium equations of steering wheel, pinion, rack and motor are:

$$
\begin{gathered}
J_{s w} \ddot{\theta}_{s w}+B_{s w} \dot{\theta}_{s w}+K_{s c}\left(\theta_{s w}-\theta_{s c}\right)=T_{s w} \\
J_{p} \ddot{\theta}_{p}+B_{p} \dot{\theta}_{p}+K_{s c}\left(\theta_{p}-\theta_{s w}\right)=N T_{m}-T_{p} \\
M_{R} \ddot{X}_{R}+B_{R} \dot{X}_{R}+F_{t}=\frac{T_{p}}{R_{p}}, X_{R}=R_{p} \cdot \theta_{p} \\
J_{m} \ddot{\theta}_{m}+B_{m} \dot{\theta}_{m}+T_{m}=T_{e} \quad, \quad \theta_{\mathrm{m}}=N \cdot \theta_{p}
\end{gathered}
$$

Once the Equations (3) and (4) are rearranged about $\theta_{\mathrm{P}}$ and substitute it to Equation (2), we can get new equations as below: 


$$
\begin{aligned}
& \left(J_{p}+R_{p}^{2} M_{R}+N^{2} J_{m}\right) \ddot{\theta}_{p}+\left(B_{p}+R_{p}^{2} B_{R}+\right. \\
& \left.N^{2} B_{m}\right) \dot{\theta}_{p}=K_{s c}\left(\theta_{s w}-\theta_{p}\right)+T_{e}-R_{p} F_{t}
\end{aligned}
$$

If $J_{e q}=J_{p}+R_{p}^{2} M_{R}+N^{2} J_{m}, B_{e q}=B_{p}+R_{p}^{2} B_{R}+N^{2} B_{m}$ then we have below equation:

$$
J_{e q} \ddot{\theta}_{p}+B_{e q} \dot{\theta}_{p}=K_{s c}\left(\theta_{s w}-\theta_{p}\right)+T_{e}-R_{p} F_{t}
$$

The equation of wheel and tire loads is the same as:

$$
F_{t}=J_{w} \ddot{X}_{R}+B_{w} \dot{X}_{R}+K_{w} X_{R}+C F_{w} \operatorname{sign}\left(\dot{X}_{R}\right)
$$

Where $C F_{w}$ is Coulomb friction breakout force on road wheel. Thus final equation is expressed as:

$$
\begin{aligned}
& \left(J_{p}+R_{p}^{2}\left(M_{R}+J_{w}\right)+N^{2} J_{m}\right) \ddot{\theta}_{p}+ \\
& \left(B_{p}+R_{p}^{2}\left(B_{R}+B_{w}\right)+N^{2} B_{m}\right) \dot{\theta}_{p}+ \\
& R_{p}^{2} K_{w} \theta_{p}+R_{p} C F_{w} \operatorname{sign}\left(\dot{\theta}_{p}\right)=K_{s c}\left(\theta_{s w}-\theta_{p}\right)+T_{e}
\end{aligned}
$$

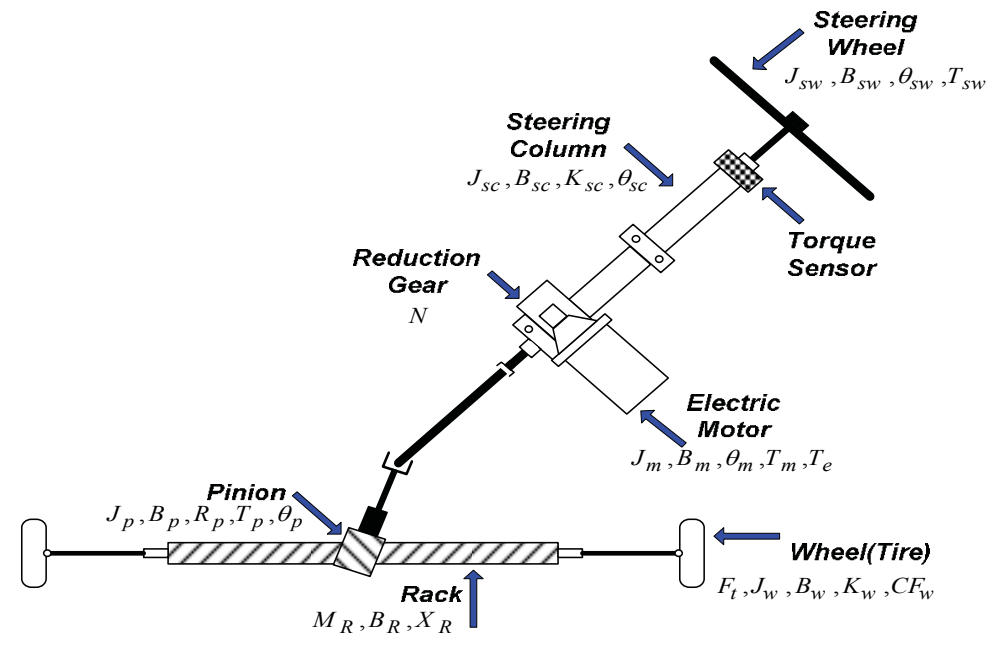

Fig. 3. Simple description of EPS Mechanism 
Using these equations, the mechanical part of EPS which incorporates the mechanical part of PMSM is modeled. The block diagram of EPS system with IPM motor and drive is shown in Fig. 4. In this block diagram the motor parameters is obtained from design and optimization procedure that mentioned in previous section. The voltage source inverter is constructed with IGBT for more accurate simulation. A current phase control technique with simple PI controller is used for simulation including a PWM module. SVPWM model is implemented by unified voltage modulation techniques (Mohan et al, 1997) And a dead time function is implemented using delay block. The control strategy which is applied to IPM motor is maximum torque per ampere up to rated speed and maximum torque per voltage (flux) over the rated speed (Lee \& Hong, 2006).

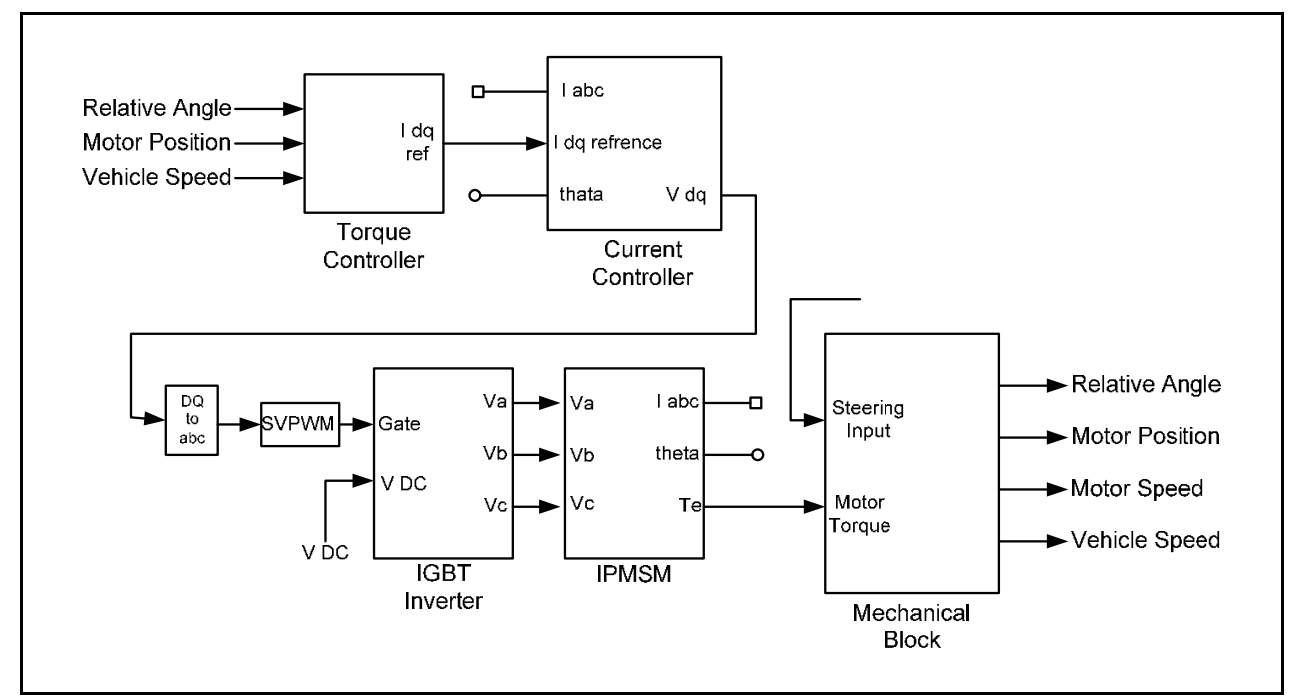

Fig. 4. A model of EPS with IPMSM Drive System

\section{System Simulation and Results}

Table 1 shows the parameters of IPMSM for EPS system simulation. These parameters are obtained by the information of motor structure, dimension and material that obtained in optimization procedure and FEM (Finite Element Method) analysis is done to obtain parameters. Stator resistance is depends on winding turns and material.

Table 1. Motor Parameters Obtained from Optimization

\begin{tabular}{|ll|c|}
\hline \multicolumn{2}{|c|}{ Motor Parameter } & VALUE \\
\hline Magnet Flux Linkage $(\mathrm{Wb})$ & 0.105 \\
\hline Stator Resistance & $(\Omega)$ & 0.02 \\
\hline d-Axis Inductance & $(\mathrm{mH})$ & 8.6 \\
\hline q-Axis Inductance & $(\mathrm{mH})$ & 22.5 \\
\hline
\end{tabular}


In simulation of electric power steering system with mechanical parts, the torque controller is simple PI controller which uses relative angle (difference between steering angle and rotor angle), motor position and vehicle speed to generate the reference value of q-axis current. $\mathrm{d}$ axis current is generated from q-axis current and maximum torque per ampere or maximum torque per flux (voltage). The current controller uses this reference values to generate $\mathrm{d}-\mathrm{q}$ reference voltages. Using these reference voltages, switching signals for IGBT inverter is constructed and system can control the IPM motor torque in order to produce needed assisted torque. DC voltage link in inverter is $12 \mathrm{~V}$ as in vehicle.

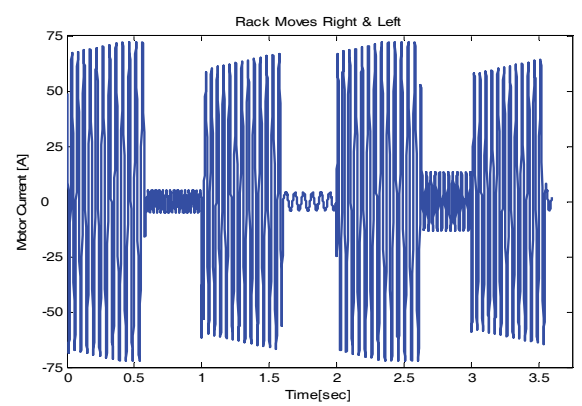

(a)

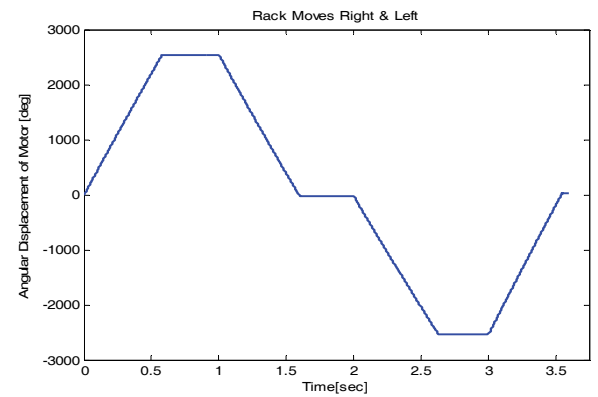

(b)

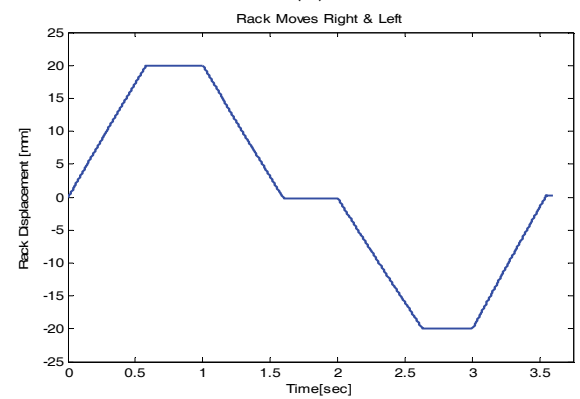

(c)

Fig. 4. Rack moves right, return back, moves left and finally return to primary position. (a) Motor Current. (b) Motor angular displacement. (c) Rack displacement. 
In the following simulations, the goal is to control the rack displacement. For example Fig 5 shows simulation results when left and right movement of rack is desired. The rack moves right up to $20 \mathrm{~mm}$, return back, moves left up to $20 \mathrm{~mm}$ and finally back to its first position. We can notify that this modeling of EPS system facsimiles the characteristics and behavior of system very similar to which we desire and command.

\section{Conclusion}

In this paper, design and optimization of interior permanent magnet motor for electric power steering application is studied. IPM motors advantages in automotive systems are discussed. Optimization is done with different objective function such as power to weight and magnet volume. After obtaining the motor parameters, we evaluate the performance of entire system through some different tests. Simulation results show that the system performance can improved using an IPM motor and drive because of its high torque density and capability of flux weakening operation. With the EPS logic for the reduction in steering torque, the driver can turn the steering wheel with a significantly reduced steering torque. With the EPS control to return to center performance, a quick response of steering wheel without overshoot after cornering can be obtained by proper control of assist motor.

\section{References}

Dave Wilson, "Electric power steering: one good turn deserves another", "Bush: No quick energy fix" Associated Press article, The Arizona Republic, pp 1, A9, Thursday, April 28, 2005.

Hooman Mohammadi and Reza Kazemi, "Simulation of Different Types of Electric Power Assisted Streering (EPS) to Inverstigate Applied Torque Positions' Effects", SAE paper No. 2003-01-0585, 2003.

L.Ingber, "Simulated annealing : practice versus theory,"Mathematical and Computer Modeling, vol.18, pp.29-57, 1993

L. Chédot, G. Friedrich, "Optimal control of interior permanent magnet synchronous integrated starter-generator," Eur. Power Elec. Drives Conf. (EPE'2003), CD Proceedings, Toulouse (France), 2003.

N. Mohan and et al., "Power Electronics and Variable Frequency Drives", IEEE PRESS, pp400453, 1997.

S. Mir, M. Islam, and T. Sebastian, "Role of electronics and controls in steering system," in Proc. 29th IEEE IECON, Roanoke, VA, Nov. 2-6, 2003, pp. 2859-2864.

T. Jahns, G. Kliman, and T. Neumann, "Interior pm synchronous motors for adjustable speed drives," IEEE Trans. Ind. Appl., vol. IA-22, no. 4, pp. 738-747, 1986.

T. Sebastian, S. Mir, M. Islam, "Electric Motors for Automotive Applications," EPE Journal, Vol.14, No.1, February 2004, pp..

Wootaik Lee, Jung-Pyo Hong, "Object oriented modeling of an Interior Permanent Magnet Synchronous Motor Drives for Dynamic Simulation of Vehicular Propulsion", IEEE Vehicle Power and Propulsion Conference, paper No. SNO-b109x, 2006.

Y. Gene Liao ,H. Isaac Du, "Modeling and analysis of electric power steering system and its effect on vehicle dynamic behavior", Int. J. of Vehicle Automotive System(IJVAS), Vol. 1, No. 2, pp. 153-166, 2003. 
Simulated Annealing.

Theory with Applications

estes by hui chibants

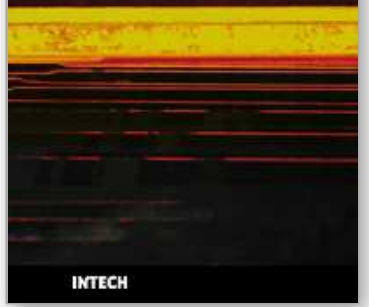

\section{Simulated Annealing, Theory with Applications}

Edited by Rui Chibante

ISBN 978-953-307-134-3

Hard cover, 292 pages

Publisher Sciyo

Published online 18, August, 2010

Published in print edition August, 2010

The book contains 15 chapters presenting recent contributions of top researchers working with Simulated Annealing (SA). Although it represents a small sample of the research activity on SA, the book will certainly serve as a valuable tool for researchers interested in getting involved in this multidisciplinary field. In fact, one of the salient features is that the book is highly multidisciplinary in terms of application areas since it assembles experts from the fields of Biology, Telecommunications, Geology, Electronics and Medicine.

\section{How to reference}

In order to correctly reference this scholarly work, feel free to copy and paste the following:

Hamidreza Akhondi, Hasan Rastegar and Jafar Milimonfared (2010). Optimal Design of an IPM Motor for Electric Power Steering Application Using Simulated Annealing Method, Simulated Annealing, Theory with Applications, Rui Chibante (Ed.), ISBN: 978-953-307-134-3, InTech, Available from:

$\mathrm{http}: / / w w w . i n t e c h o p e n . c o m / b o o k s / s i m u l a t e d-a n n e a l i n g--t h e o r y-w i t h-a p p l i c a t i o n s / o p t i m a l-d e s i g n-o f-a n-i p m-$ motor-for-electric-power-steering-application-using-simulated-annealing-met

\section{INTECH}

open science | open minds

\section{InTech Europe}

University Campus STeP Ri

Slavka Krautzeka 83/A

51000 Rijeka, Croatia

Phone: +385 (51) 770447

Fax: +385 (51) 686166

www.intechopen.com

\section{InTech China}

Unit 405, Office Block, Hotel Equatorial Shanghai

No.65, Yan An Road (West), Shanghai, 200040, China

中国上海市延安西路65号上海国际贵都大饭店办公楼 405 单元

Phone: +86-21-62489820

Fax: $+86-21-62489821$ 
(C) 2010 The Author(s). Licensee IntechOpen. This chapter is distributed under the terms of the Creative Commons Attribution-NonCommercialShareAlike-3.0 License, which permits use, distribution and reproduction for non-commercial purposes, provided the original is properly cited and derivative works building on this content are distributed under the same license. 